\title{
Water retention characteristics of soil bio-amendments used as growing media in pot culture
}

\author{
S.S. Kukal1*, Debasish Saha ${ }^{1}$, Arnab Bhow mik ${ }^{1}$ and R.K. Dubey ${ }^{2}$ \\ ${ }^{1}$ Department of Soil Science, ${ }^{2}$ Department of Floriculture and Landscaping, Punjab Agricultural University, Ludhiana, \\ 141004, India.*E-mail: sskukal@rediffmail.com
}

\begin{abstract}
The efficacy of the natural bio-amendments in improving physical condition as well as water retention characteristics of the growing media in pot culture was studied on ten different compositions of growing media. The treatments comprised of (i) soil as sole medium; (ii) soil + sewage sludge (SS) in the ratio of 1:1; (iii) soil + SS + coir (CP) in the ratio of 1:1:1; (iv) soil + vermicompost (VC) in the ratio of $1: 1$; (v) soil + VC + CP in the ratio of 1:1:1; (vi) soil + farmyard manure (FYM) in the ratio of 1:1; (vii) soil + FYM + CP in the ratio of 1:1:1; (viii) soil + SS + VC in the ratio of 1:1:1; (ix) soil + SS + FYM in the ratio of 1:1:1 and (x) soil + FYM + VC in the ratio of 1:1:1. The bulk density of media composition soil+SS+CP, soil+VC+CP and soil+FYM+CP was 24.2 , 27.5 and $27.5 \%$ lower than the media containing only soils $\left(1.32 \mathrm{mg} \mathrm{m}^{-3}\right)$, respectively. The water holding capacity (WHC) was lowest (45.4\%) in sole soil treatment and it was 6.3, 5.6 and 6.1 times higher in soil+SS+CP, soil+VC+CP and soil+FYM+CP, respectively. The volumetric water retention at various suctions was significantly improved by addition of the organic amendments with soil. The magnitude of the differences in water retention among the treatments became wider at the higher suctions. The combination of soil+VC+CP showed the highest amount of water retention among all the treatments at all the suctions. The air filled porosity was highest (190.7\%) in soil+FYM+CP media and lowest (25.3\%) in sole soil media. Significant increase in easily available water was observed with the incorporation of coir with sewage sludge, vermicompost and FYM. The water buffering capacity was lowest in media with only soil (7.56\%) and the media containing soil+VC+CP recorded the highest (24.7\%) water buffering capacity.
\end{abstract}

Key words: Bio-amendments, growing media, bulk density, water retention, air filled porosity, easily available water, water buffering capacity

\section{Introduction}

The commercial use of different organic growing media as bioamendments in soil used in nurseries and greenhouse crops is very common due to their healthy effects on the soil physical environment. The suitable use of growing media is of importance for production of quality greenhouse crops. It directly influences the growth, development, ramification and functioning of rooting system (Argo, 1998; Richards and Beardsell, 1986). It is important to maintain the optimum aeration and water status of the media to avoid the drought or excess water stress due to the shallow depth and limited volume of soil in the containers. The ability of the growing media to make a healthy balance between water content and gaseous exchange is critical for the keeping quality of the ornamental plants (Dressboll, 2010). Thus, the organic soil amendments are usually mixed with soil to provide the optimal physical and chemical environment (Yangyuoru et al., 2006) to the growing plants. This also buffers the temporary water stress and plant failure during the establishment stage (De Boodt, 1990; Johnson and Leah, 1990). Solely field soils are generally not recommended for pot culture purpose as they do not provide the required aeration, drainage and water holding capacity which results in suppression of root growth and susceptibility to soil borne diseases (Beattie and White, 1992). Thus, several bio-amendments have recently been used in nurseries and greenhouses. The coir, farmyard manure (FYM), sewage sludge, vermicompost are the most commonly used growing media in the greenhouses and pot culture. Recently the use of coir or coconut mesocarp as a substitute of sphagnum peat has been well accepted in horticultural nurseries (Yau and Murphy, 2000; Pickering, 1997) because of its better physical properties (Evans et al., 1996; Prasad, 1997) and excellent ability to make a balanced air and water supply to the roots. These non-soil materials can be manipulated or processed in different ratios and combinations to provide the superior physical and chemical environment for optimum plant growth. Thus the success of plants grown in pot culture can be summed up by the physical attributes of the growing media that influences its ability to provide sufficient water to the root systems without any oxygen shortage (Michel, 2010; Khayyat et al., 2007) which is the most determining factor in containerised cultivation.

The good physical environment means the physical make up of the growing media viz., maximum water holding capacity (WHC), bulk density of the mixture, air-filled porosity (AFP), water retention characteristics at a particular matric potential and the mechanical support to the plant growth. The AFP is the volume of air in a media mix after it has been watered heavily and then allowed to drain. If the media mix is very dense and there is too little air in the media mix (less than 10\%) then the roots will not be properly aerated and the plant will suffer, especially in a medium like pot having limited drainage capacity. Although plants can extract more than the available water, they will need to exert extra energy to do so and this restricts their growth. The balance between the available water and the air space depends on the size and shape of the particles in the media or more precisely the pores 
between the solid particles. Therefore, the ideal mix should have a balance between medium and coarse particles with a minimum of fine particles. Thus, the present study was conducted to evaluate the physical and water retention characteristics of different combinations of soil and bio-amendments so as to identify the best blend for easy availability of water and air to the plants.

\section{Materials and methods}

The experiment was conducted at Punjab Agricultural University, Ludhiana, India. Four different soil bio-amendments viz. FYM, vermicompost, coir and sewage sludge were used for evaluating their effect on soil water retaining characteristics on mixing with soils at different proportion and combinations. The treatments consisted of ten different combinations of soil and non-soil organic amendments in equal proportion. The treatments comprised of (i) soil as sole medium; (ii) soil + sewage sludge (SS) in the ratio of $1: 1$; (iii) soil + SS + coir (CP) in the ratio of $1: 1: 1$; (iv) soil + vermicompost (VC) in the ratio of $1: 1$; (v) soil + VC + CP in the ratio of 1:1:1; (vi) soil + farmyard manure (FYM) in the ratio of $1: 1$; (vii) soil + FYM + CP in the ratio of 1:1:1; (viii) soil + SS $+\mathrm{VC}$ in the ratio of 1:1:1; (ix) soil + SS + FYM in the ratio of 1:1:1 and (x) Soil + FYM + VC in the ratio of 1:1:1.

The organic amendments were dried under shade and then different treatment combinations were prepared by mixing them thoroughly by hand at equal proportions (w/w) to make it homogeneous. In case of coir, the raw sample was used without any grinding except removal of the knots.

Pot filling: The growing media was packed in the pots with a preselected compaction level. The soil mixed with bioamendments in the desired proportions was filled in $30 \mathrm{~cm}$ high polyvinyl chloride (PVC) pots having internal diameter of $20 \mathrm{~cm}$. The PVC pots had a hole of $1 \mathrm{~cm}$ diameter at the bottom end so as to drain the excess water. The soil along with bioamendments were filled in the pots in small lots with 30 strokes using a wooden rod with cone-shaped pointed end. This was done to attain a uniform packing of different mixtures of soil and bioamendments. The pots were irrigated till near saturation and were then allowed to attain the equilibrium for 2-3 days. The treatments of the mixtures of growing medium were replicated thrice. In-situ sampling was done for determination of different physical characteristics from these pots.

Bulk density: The bulk density was measured by core method (Blake and Hartge, 1986). A metallic core of $5 \mathrm{~cm}$ inner diameter and $5 \mathrm{~cm}$ height was inserted in the packed pots to take out undisturbed sample of the growing media mixture. The sample was then dried in an oven at $105^{\circ} \mathrm{C}$ for $24 \mathrm{~h}$ or till the sample weight became constant. The ratio of oven-dry weight of the sample in the core and the internal volume of metallic core was expressed as bulk density.

Water holding capacity: The water holding capacity (\%) was determined as per Richard (1954). It was computed as follows:

WHC (\%) $=100 x \frac{W_{s w}-W_{s d}-W_{f}}{W_{s d}-W_{k}-W_{g}}$

Where, $\mathrm{W}_{\mathrm{sw}}$ is the weight of watch glass + Keen's box + filter paper + saturated sample in $\mathrm{g}$; $\mathrm{W}_{\mathrm{sd}}$ is the weight of watch glass +
Keen's box + filter paper + oven dry sample in $\mathrm{g} ; \mathrm{W}_{\mathrm{k}}$ is the weight of Keen's box + filter paper in $\mathrm{g} \mathrm{W}_{\mathrm{g}}$ is weight of watch glass in $\mathrm{g}$; and $\mathrm{W}_{\mathrm{f}}$ is weight of water absorbed by filter paper.

Water retention characteristics: Water retention at various soil matric suctions was determined with the help of Richard's pressure plate apparatus (Richard, 1949). For this purpose, the cores sampled for bulk density measurement were sliced so as to fit in retainer rubber rings on the porous, saturated ceramic plate. These were then saturated overnight along with the ceramic plates with an excess of water maintained in the tray. The ceramic plate along with the saturated samples was placed in the pressure plate chamber and connected to an outflow tube. The required pressure equivalent to desired soil matric potential was maintained by the air compressor fitted with suitable pressure regulator so as to equilibrate the sample at required suction levels. After the equilibrium was attained, the samples were immediately transferred to the moisture box and the moisture content at particular suction was determined gravimetrically by drying the samples in an oven at a constant temperature of $105^{\circ} \mathrm{C}$ for 24 hours. The relationships between volumetric water content versus the soil matric suction were expressed in the form of soil moisture characteristics curves. These water retention curves were used to estimate the following parameters as suggested by Michel (2010).

The air-filled porosity, defined as the volumetric proportion of the water contained at saturation (water potential $=0 \mathrm{kPa}$ ) in the coarsest pores and therefore, readily released and replaced by air at water potentials between 0 and $-1 \mathrm{kPa}$.

The easily available water, which is the volumetric proportion of water retained in the growing medium by forces which are compatible with root extraction capacity (defined for the range of water potential from $-1 \mathrm{kPa}$ to $-10 \mathrm{kPa}$ ).

The water buffering capacity, defined as the volumetric proportion of water released by the growing medium between -5 and $-10 \mathrm{kPa}$, enabling physiological adaptation of the plant to the changing water potential.

Statistical analysis: The data was analyzed using analysis of variance (ANOVA) in a completely randomised design, so as to estimate the critical difference among the treatments. Regression analysis was carried to study the significance of relationship between water holding capacity (WHC) and bulk density. Least significant difference (LSD) at 95\% probability level was employed to compare the treatment means.

\section{Results and discussion}

Bulk density: Analysis of variance showed significant $(P<0.05)$ differences in bulk density among the growing media (Fig.1). The influence of bio-amendments incorporation with soil on media bulk density was more pronounced in case of coir treatments. The bulk density of media containing soil+SS+CP, Soil+VC+CP and soil+FYM+CP was significantly lower than the other treatments. It was 24.2, 27.5 and $27.5 \%$ lower than the media with sole soil (1.32 $\mathrm{Mg} \mathrm{m}^{-3}$ ), respectively. Sudhagar and Sekar (2009) reported the decrease in bulk density and particle density with increase of coir could be due to light weight of coir and increased pore space (Saravanan and Nambisan, 1995). On the contrary the application 


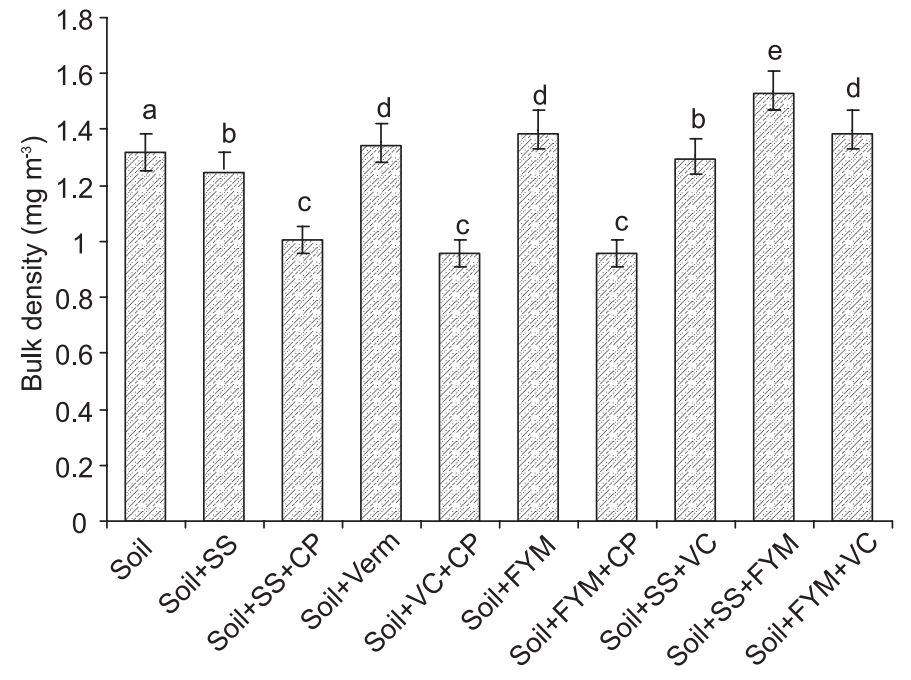

Fig.1. Bulk density of soil as affected by different non-soil bioamendments. (Vertical columns are means and the bars on each column are \pm standard errors of mean; lower case letters indicate differences at the 0.05 probability level in bulk density among the treatments)

of vermicompost and FYM slightly increased the media bulk density as compared to control (only soil). The application of sewage sludge (soil+SS) reduced the media bulk density by $6 \%$ than the control media. Subsequent addition of coir further reduced the bulk density of media composition soil+SS+CP by $19.3 \%$. On the contrary, the application of FYM increased the bulk density by 23\% in Soil+SS+FYM media combination than the Soil+SS treatment. Differences in results obtained here are most likely due to the variation in particle-size distribution of the material (Richards and Beardsell, 1986). Being fibrous, the coir fibers evenly spread in the soil and due to its lighter weight it reduces the bulk density with concomitant increase in total porosity (Awang et al., 2009). The lower bulk density with coir media facilitates the mixing and incorporation of the media, easy transportation and sufficient aeration to the plants.

Water holding capacity: The water holding capacity (WHC) significantly differed among the different media combinations (Fig. 2). With the application of organic amendments there was a significant increase in WHC among the treatments as compared to

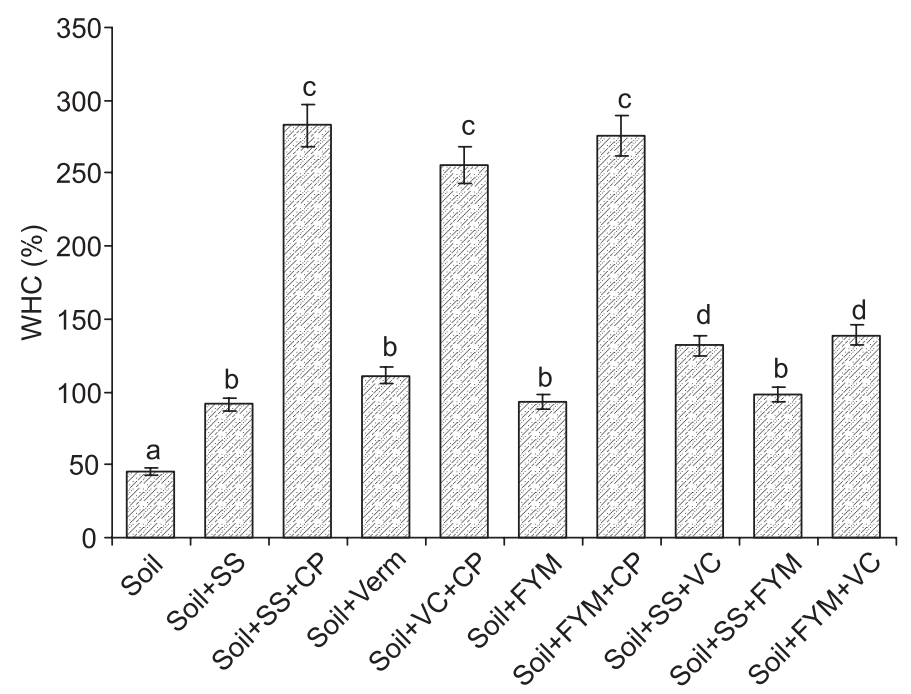

Fig. 2. Water holding capacity of soil as affected by different non-soil bioamendments. (Vertical columns are means and the bars on each column are \pm standard errors of mean; lower case letters indicate differences at the 0.05 probability level in WHC among the treatments) the control with no amendments. The prominent beneficial effect of coir on soil physical make up is manifested by Fig. 2. The three coir treatments, soil+SS+CP, soil+VC+CP and soil+FYM+CP exhibited significantly higher WHC as compared to the other treatments. The WHC was lowest (45.4\%) in media with sole soil and 6.3, 5.6 and 6.1 times higher in soil+SS+CP (283\%), soil+VC+CP (256\%) and soil+FYM+CP (276\%), respectively. There was non-significant difference in WHC with the application of sewage sludge, FYM and vermicompost addition with the soil as in soil+SS, soil+VC and soil+FYM treatments. The differences in the WHC among the media could be due to the diversity in total porosity and pore-size distribution. The light weight, fibrous coir adds higher porosity and reduced bulk density that helps in holding higher amount of water. The higher WHC of coir based media due to its higher total porosity has also been reported by Evans et al. (1996) and Prasad (1997). Several experiments have revealed that use of coir alone or as a component of soil medium is suitable for various potted plants (De Kreij and Leeuven, 2001; Treder, 2008) as well as vegetable crops. There was a linear correlation $\left(\mathrm{R}^{2}=0.75\right)$ (Fig. 3) between bulk density and WHC of the growing media. With the increase in bulk density there was a linear decrease in WHC. Thus the significantly lower bulk density of the coir treatments renders the significantly higher WHC as compared to other treatments.

Water retention characteristics and aeration: The water retention characteristics are basically the capability of the media to retain water at different moisture potentials. The water retention curves of different media compositions have been presented in Fig. 4. Significant differences were observed in water retention among the treatments under different soil moisture suctions except in Fig. 4d, where there was not much difference among the treatments. The difference in water retention among the treatments is narrow in the lower suction range and the magnitude of difference increases with the increase in suction value. Awang et al. (2009) reported that at the initial values of soil water suction, the volume of water held by different media was more or less similar. Among all the treatments the media with only soils as growing media retained lowest amount of water at all the suctions. The application of sewage sludge with soil (soil+SS) caused 2 times increase in water retention at 1 bar of soil water suction whereas, with the incorporation of coir with soil and sewage

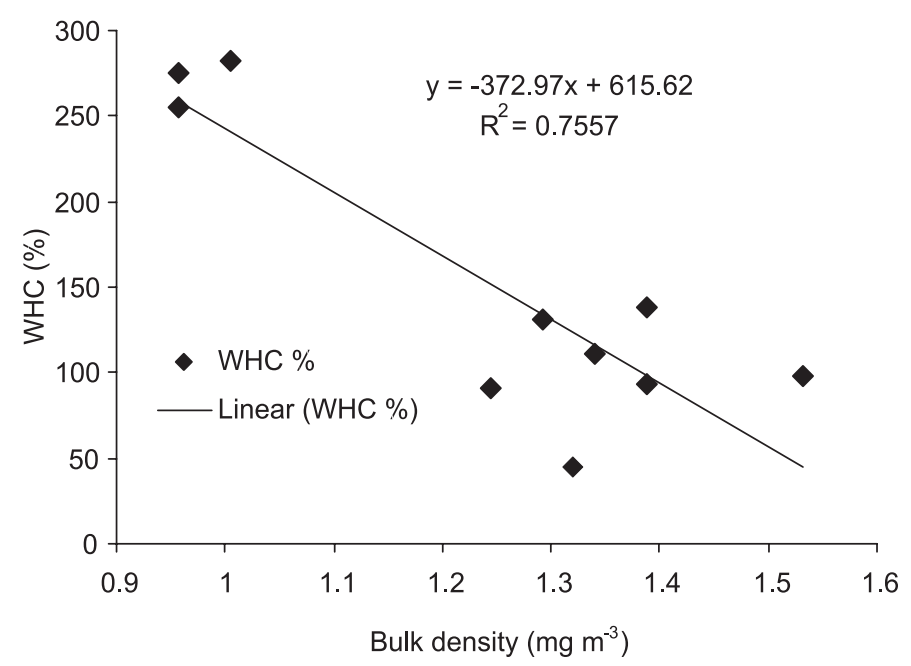

Fig. 3. Relationship between bulk density and water holding capacity of the growing media 

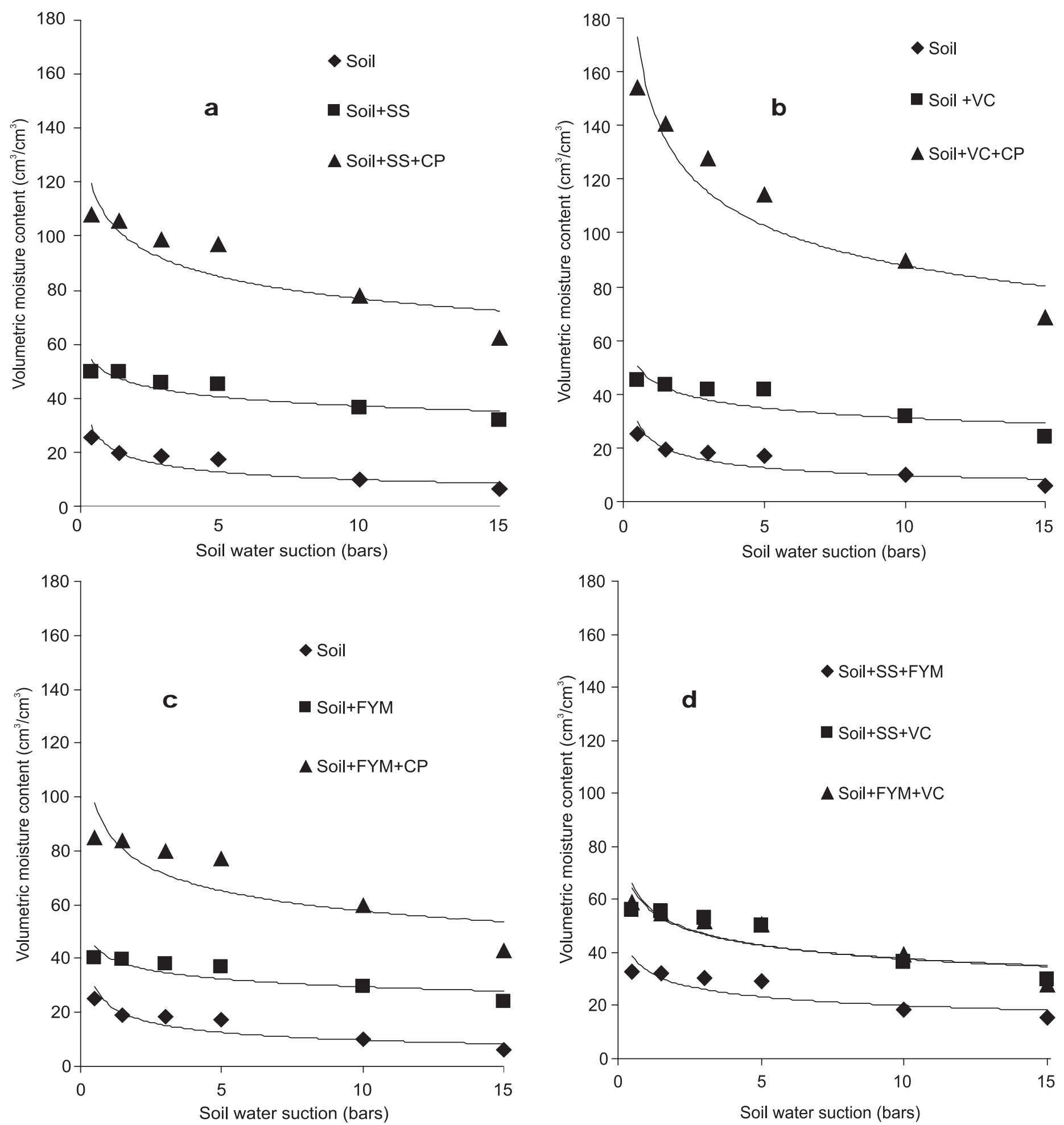

Fig. 4. Water retention characteristics of different growing media as affected by different non-soil bio-amendments in different proportions and combinations

sludge (soil+SS+CP) caused 4.3 times higher water retention at the same soil water suction (Fig. 4a). With the increase in suction the volume of water retained decreased in all the media but the magnitude of differences among the treatments increased. This indicated that the application of organic amendments improves water retention even at higher suctions as compared to sole soils. This is one of the important attributes of using bio-amendments as growing media that could be exploited to avoid the drought stress in the greenhouses. This is mainly due to the restricted movement of water from subsurface to surface because of reduced evaporation (Ouchi et al., 1990). The combination of soil+VC+CP showed the highest amount of water retention among all the treatments at all the suctions. The effect of coir was less prominent when it is mixed with soil and FYM (soil+FM+CP) (Fig. 4c). The remarkable increase in water retention of media with non-soil organic amendments (especially coir) as compared to media with sole soil is due to the predominant role of the organic amendments on soil physical properties. The microbial decomposition of the organic amendment compounds releases by-products like polysaccharides and polyuronoides (Hillel, 1980) which helps 
in stabilising aggregates by enmeshing the soil particles within the aggregates. The water retention, air-filled porosity and gas diffusion are mainly dependent on particle size of the growing media and the pores between the particles (Caron and Nkongolo, 1999; Caron et al., 2005). The pore continuity is the most critical physical factor influencing water dynamics and gas exchange by roots (Gruda and Schnitzler, 2004). Evans et al. (1996) and Verhagen (2004) have shown the increased water retention of peat media with the addition of coco peat or coir dust. The positive effect of coir on soil physical environment has also been reported by Managecraft (2001).

The air filled porosity as calculated from the water retention curve was significantly differed among the treatments (Table 1). It was highest (190.7\%) in soil+FYM+CP combination and lowest (25.3\%) in sole soil treatment. The application of coir with sewage sludge (soil+SS+CP) and vermicompost (soil+VC+CP) caused 6.9 and 4 times increase in air filled porosity as compared to media with only soil, respectively. Ensuring proper aeration for proper root growth in pots in greenhouse and nurseries is a real challenge for the growers because of impeded drainage due to limited soil volume in the container. Aeration basically depends on the media pore size. Watering in the pots causes saturation of the total porosity. As the media dries up, water first depletes from the larger pores. Application of coir improves the macro porosity of the media and helps in draining excess water and maintains the proper aeration status. Increased proportion of larger pores enhances more aeration after drainage (Handreek and Black, 2007). Khayyat et al. (2007) observed significant differences on growth performances of Epipremnum aureum Lindl. and Andre ('Golden Pothos') grown on coir based rooting media. They explained the large differences on rooting quality and shoot characteristics by the direct effect of growth substrate on the basal portion of cutting rather than the indirect or earlier physiological changes. Improved root formation and growth in coir mixtures could be due to better aeration, drainage conditions and water maintenance capability of the substrate (Eleni et al.,

Table 1. Air-filled porosity and water availability in different compositions of bio-amendments in soil

\begin{tabular}{lccc}
\hline Media composition & $\begin{array}{c}\text { Air filled } \\
\text { porosity } \\
(\%)\end{array}$ & $\begin{array}{c}\text { Water } \\
\text { availability } \\
(\%)\end{array}$ & $\begin{array}{c}\text { Water } \\
\text { buffering } \\
\text { capacity (\%) }\end{array}$ \\
\hline Soil & $25.3^{\mathrm{a}}$ & $10.2^{\mathrm{a}}$ & $7.36^{\mathrm{a}}$ \\
Soil+SS (1:1) & $41.9^{\mathrm{b}}$ & $13.3^{\mathrm{a}}$ & $8.17^{\mathrm{a}}$ \\
Soil+SS+CP (1:1:1) & $175.4^{\mathrm{c}}$ & $30.3^{\mathrm{b}}$ & $19.3^{\mathrm{b}}$ \\
Soil+VC (1:1) & $66.0^{\mathrm{d}}$ & $13.5^{\mathrm{a}}$ & $10.0^{\mathrm{a}}$ \\
Soil+VC+CP (1:1:1) & $101.3^{\mathrm{e}}$ & $64.7^{\mathrm{c}}$ & $24.7^{\mathrm{c}}$ \\
Soil+FYM (1:1) & $53.2^{\mathrm{f}}$ & $10.3^{\mathrm{a}}$ & $6.90^{\mathrm{a}}$ \\
Soil+FYM+CP (1:1:1) & $190.7^{\mathrm{g}}$ & $25.4^{\mathrm{d}}$ & $17.7^{\mathrm{b}}$ \\
Soil+SS+VC (1:1:1) & $75.3^{\mathrm{d}}$ & $20.0^{\mathrm{e}}$ & $13.8^{\mathrm{a}}$ \\
Soil+SS+FYM (1:1:1) & $65.5^{\mathrm{d}}$ & $14.1^{\mathrm{a}}$ & $10.8^{\mathrm{a}}$ \\
Soil+FYM+VC (1:1:1) & $79.8^{\mathrm{h}}$ & $19.6^{\mathrm{e}}$ & $11.7^{\mathrm{a}}$
\end{tabular}

The dissimilar lower case letters indicate significant differences among the treatments at $P<0.05$

$\mathrm{SS}=$ sewage sludge; $\mathrm{CP}$ = cocopeat; $\mathrm{VC}$ = vermicompost;

FYM = farmyard manure
2001; Noguera et al., 2000) which are critical for the first phase of the root initiation. The effect of sewage sludge, vermicompost and FYM on increasing water availability only happened when they were associated with coir (Table 1). Mere application of sewage sludge, vermicompost and FYM did not significantly affect the water availability in soil+SS, soil+VC and soil+FYM treatments as compared to sole soils. Significant increase in water availability was observed with the incorporation of coir with sewage sludge, vermicompost and FYM. The effect of coir application on water availability is very clear in soil $+\mathrm{SS}+\mathrm{CP}$, soil+VC+CP and soil+FYM+CP treatment combinations where there were 2.9, 6.3 and 2.5 times higher water availability as compared to the control treatment, respectively (Table 1). Similar trend was observed in case of water buffering capacity of the media (Table 1). The media with only soil had the lowest (7.36\%) water buffering capacity and the media containing vermicompost and coir associated with soil recorded the highest (24.7\%) water buffering capacity. The higher water availability of the coir containing media indicates more available water to the plants. At the same time high water buffering capacity of the coir makes it more flexible in providing irrigation and less restrictive in terms of water management (Michel, 2010).

The study of organic amendments on water retention properties showed that the non soil organic amendments have a positive effect on physical environment of the media and hence improve the water retention and aeration properties of the media. The impact of coir, which is environmentally safe and cheap, was much more pronounced among the organic amendments. The application of coir in association with vermicompost, FYM or sewage sludge rather than their individual use is found to be a viable option for providing better aeration, water availability to the plants as well as water buffering capacity of the media which has long been a challenge for pot culture in greenhouses and nurseries.

\section{References}

Argo, W.R. 1998. Root medium physical properties. Hort. Technol., 8: 481-485.

Awang, Y., A.S. Shaharom, R.B. Mohamad and A. Selamat, 2009. Chemical and physical characteristics of cocopeat-based media mixtures and their effects on the growth and development of Celosia cristata. Am. J. Agric. Biol. Sci., 4: 63-71.

Beattie, D.J. and J.W. White, 1992. Lilium-hybrids and species. In: The Physiology of Flower Bulbs. A. De Hertogh and M. Le Nard (eds.). Elsevier, Amsterdam.

Blake, G.R. and K.H. Hartge, 1986. Bulk density. In: Methods of Soil Analysis, Part I, A. Klute (ed). ASA Monograph No 9. Madison, WI. p.363-376.

Caron, J., L.M. Riviere and G. Guillemain, 2005. Gas diffusion and airfilled porosity: effect of some oversize fragments in growing media. Canadian J. Soil Sci., 85: 57-65.

Caron, J. and N.V. Nkongolo, 1999. Aeration in growing media: recent developments. Acta Hort., 481: 545-551.

De Boodt, M. 1990. Application of polymeric substances as physical soil conditioners. In: Soil Colloids and their Association in Soil Aggregates. (M. De Boodt et al., ed.), Planum Publishing Corporation, London, New York. p. 580-592.

De Kreij, C. and G.J.L. Leeuven, 2001. Growth of pot plants in treated coir dust as compared to peat. Commun. Soil Sci. Plant Anal., 32: 2255-2265. 
Dressboll, D.B. 2010. Effect of growing media composition, compaction and periods of anoxia on the quality and keeping quality of potted roses (Rosa sp.). Scientia Hort., 126: 56-63.

Eleni, M., K. Sabri and Z. Dimitra, 2001. Effect of growing media on the production and quality of two rose varieties. Acta Hortic., 548: 79-83.

Evans, M.R., S. Konduru and R.H. Stamps, 1996. Source variation in physical and chemical properties of coconut coir dust. Hort. Sci., 31: 965-967.

Gruda, N. and W.H. Schnitzler, 2004. Suitability of wood fiber substrate for production of vegetable transplants. I. Physical properties of wood fiber substrates. Scientia Horti., 100: 309-322.

Handreck, K.A. and N.D. Black, 2007. Growing Media for Ornamental Plants and Turf. 3rd Edn., UNSW Press, Sydney, ISBN:13:9780868407968.

Hillel, D. 1980. Fundamentals of Soil Physics. Academic Press, New York. p.113-117.

Johnson, M.S. and R.T. Leah, 1990. Effects of super absorbent polyacrylamide on efficacy of water use by crop seedlings. J. Sci. Fd Agric., 52: 431-434.

Khayyat, M., F. Nazari and H. Salehi, 2007. Effects of different pot mixtures on pothos (Epipremnum aureum Lindl. and Andre 'Golden Pothos') growth and development. American-Eurasian J. Agric. Environ. Sci., 2: 341-348.

Managecraft, 2001. Results of Analysis of Coconut Husk Fibre or CocoPeat. Managecraft (GH) Ltd., Box 207. Takoradi, Ghana.

Michel, J. 2010. The physical properties of peat: a key factor for modern growing media. Mires Peat., 6: 1-6.

Noguera, P., M. Abad, V. Noguera, R. Puchades and A. Maquieira, 2000. Coconut coir waste, a new and viable ecologically friendly peat substitute. Acta Hort., 517: 279-286.
Ouchi, S., A. Nishikawa and E. Kameda, 1990. Soil-improving effect of a super-water-absorbent polymer. II. Evaporation, leaching of salts and growth of vegetables. Jap. J. Soil Sci. Pl. Nutr., 61: 606-613.

Pickering, J.S. 1997. An alternative to peat. The Garden, 122: 428429.

Prasad, M. 1997. Physical, chemical and biological properties of coir dust. Acta Hort., 450: 21-29.

Richard, L.A. 1949. Pressure membrane apparatus construction and use. Agri. Engg., 28: 451-454.

Richard, L.A. 1954. Diagnosis and Improvement of Saline and Alkali Soils: Agriculture Handbook No. 60. USDA. New York.

Richards, D.M.L. and D.V. Beardsell, 1986. The influence of particlesize distribution in pinebark:sand:brown coal potting mixes on water supply, aeration and plant growth. Scientia Hort., 29: 1-14.

Saravanan, A. and K.M.P. Nambisan, 1995. Utilization of coco peat as pot culture medium for Begonia semperflorense. Madras Agric. J., 82: 587-589.

Sudhagar, R. and K. Sekar, 2009. Effect of coco peat medium on growth and quality of poinsettia (Euphorbia pulcherrima. Wild.). The Asian J. Hort., 4: 52-56.

Treder, J. 2008. The effect of cocopeat and fertilization on the growth and flowering of oriental Lily 'Star Gazer'. J. Fruit Ornamental Plant Res., 16: 361-370.

Verhagen, J.B.G.M. 2004. Effectiveness of clay in peat based growing media. Acta Hort., 644: 115-122.

Yau, P.Y. and R.J. Murphy, 2000. Biodegraded cocopeat as a horticultural substrate. Acta Hort., 517: 275-278.

Yangyuoru, M., E. Boateng, S.G.K. Adiku, D. Acquah, T.A. Adjadeh and F. Mawunya, 2006. Effects of natural and synthetic soil conditioners on soil moisture retention and maize yield. West Africa J. Applied Ecol., 9: 1-8.

Received: February, 2012; Revised: October, 2012; Accepted: December, 2012 